\title{
Two Decades of High School Curriculum Change In Oklahoma
}

\section{F. A. BALYEAT}

I $N$ this study of the recent curriculum changes in the high schools of Oklahoma, the most recent data obtainable were used-those found in the 1949 Annual High-School Bulletin, issued by the State Department of Education. The bulletins of 1929 and 1939 were used to get comparable figures. These are all three very significant years. The first represented the peak of development of the prosperous 1920's, before the effects of the depression were felt. By 1939 the schools had somewhat recovered from financial shortages and had profited by opportunities revealed in the previous decade, yet World War II had not yet affected high-school conditions. In 1949 much of the effect of the war on high-school offerings was still evident, though some of the changes were declining. Again vision and opportunity combined to modify the curriculum opportunities of Oklahoma youth.

One hundred high schools were selected for which curriculum data could be had for all three years. Any school which was a member of the North Central Association any one of the three years could not be used, because, prior to 1949, the offerings of North Central schools were not shown in the bulletin. Those with twenty or more units of accredited work for each of the three years were selected. To get one hundred, it was necessary to include $a_{i}$ very few with slightly fewer than twenty units in one of the three years.

The major changes are shown; some very interesting and significant phases are not included in a study of this length. These are revealed in the complete table which has been prepared from the tabulations and which is still being developed. In general, the academic offerings steadily declined in favor of more recent additions to the secondary curriculum. The boy or girl not likely to attend college is remembered in these curriculum changes. The "persistent needs" of all youth are reflected in some of the changes. So, too, are their

F. A. Balyeat is Professor of Secondary Education in the College of Education, University of Oklahoma, Norman, Oklahoma. 
major interests and their varying capacities and talents much better cared for in the 1949 offerings than in those of the previous years. In the following reports, the work of grades nine to twelve is included, regardless of local organization.

\section{ENGLISH}

There was less change in amount of English offering, as such, than in any other department. Most schools show four units of English for each of the three years, though a few showed five in 1949. This figure includes the usual courses in composition, grammar, and literature.

The major English change was shown in the number of schools offering credit courses in speech and the change in the total amount of credit work provided, nearly always elective. In 1929 fifty-six of the one hundred schools offered credit courses in speech. This increased to seventy-six in 1939 and then dropped to seventy-one in 1949. But in 1929, twenty-eight of the schools gave only a half-unit course and none of them provided more than one unit. Steadily the schools with only a half-unit have declined until in 1949 only four provided so little. Three offered three units in 1949.

Business English is for commercial majors and usually taught by a member of that staff, always for one-half unit. Often other pupils have elected this course, partly because of its very practical nature. In 1929, twenty-six of the group of schools offered this course. It increased to thirty-three in 1939 and then dropped sharply to eighteen in 1949.

\section{SOCIAL STUDIES}

Undesignated history courses reflected one of the biggest changes. In 1929 there were sixty-five of these hundred schools that offered four or five units of history. This declined to three in 1939 and none was tabulated for 1949. In the last year of the study, ninety per cent of these schools did not provide more than two units of undesignated history work. One unit of United States history is universal, the others varying, with world history gaining in recent years.

Oklahoma history and community civics, for a semester each, were suggested in 1929 by the State Department committee that studied curricular reorganization for small high schools in Oklahoma. This suggestion was generally and rapidly accepted so that by 1939 there were ninety-six per cent of the schools offering this combination. In 1949 it had dropped to ninetyone per cent. This is usually a required year of work in the ninth grade.

Economics and sociology, with advanced civics less frequent, characterized the elective offerings in the upper grades. The committee referred to above suggested problems of American democracy for either a semester or a year. 
This suggestion, too, met with ready acceptance. Already (in 1928-29) there were seventeen schools giving this course. They increased to sixty-eight in 1939 and then dropped to fifty-one in 1949. One or two semesters of economics and/or sociology continue, but the number dropped from seventy-six in 1929 to thirty-three in 1939 and to thirty-two in 1949.

\section{SCIENCE}

General science, usually for a unit, is the prevailing offering and requirement in science among these schools. Entering Oklahoma high schools in 1915 , this course steadily gained ground as a ninth-grade science offering until by 1929, eighty-one per cent of this group of schools offered it. This increased to ninety-five per cent in 1939 and to ninety-eight per cent in 1949.

Biology is the next science offering, both in number of schools giving and students taking. In 1929 there were twenty-two of these one hundred schools that had zoology and/or botany, for a semester each. Then only thirty-six offered biology, as such. The number increased to seventy-seven in 1939 and to seventy-eight in 1949, with separate courses in botany and zoology very rarely found. Physiology was offered as a separate one-semester subject in 1929 in forty-five per cent of these schools. It had dropped to six schools in 1939 and to five in 1949. However, this subject is now fairly well included in most of the biology courses, but with less emphasis on human health. In 1949 a half-unit or a unit of health and physical education was given by six of these schools.

A semester each of physical and commercial geography has characterized the science offering of schools of this size through the years. Really, commercial geography is much more a social study, though often considered a science and allowed to satisfy a science requirement.

Physics, once offered by all four-year schools and taken by most pupils who were graduated, was given in twenty-six of these schools in 1929. Dropping to thirteen in 1939, it returned to eighteen in 1949, probably a result of interest developed during the war. Chemistry, starting with only seven schools in 1929, rose to sixteen in 1939 and on up to twenty-two in 1949. Five of these one hundred schools offered both physics and chemistry in 1949.

\section{MATHEMATICS}

Several extreme fluctuations are found in mathematics offering during these two decades. In the nineteen-twenties, a three-year sequence of general mathematics became common in the larger junior high schools. The State Department Committee on Curricular Reorganization recommended in the summer of 1929 that a one-year "composite" mathematics course be offered in the ninth grade, at first intended mainly for noncollege-bound students 
with little interest and often too meager capacity in algebra. It was to be a substitute for algebra for them and further preparation for successful work is beginning algebra for some others. By 1939 there were seventy-eight of these hundred schools offering the one-unit course in composite, or general, mathematics. In 1949 there were only sixty-one.

Algebra showed the greatest changes, brought on in part by the war and in part by the revealed need for more algebra proficiency on the part of college entrants. In 1929, there were forty-three of these schools offering one unit of algebra, the others giving three semesters. By 1939 the number giving a unit and a half had declined from fifty-seven to forty-four. The 1949 reports show thirty-three schools giving one unit, twenty-three giving one and a half units, and forty-four giving two units. How many took the advanced courses in each of the years would present an interesting study.

Geometry remains a regular offering in these schools, but the extent of the offering has declined. The number giving solid geometry declined from twenty-two in 1929 to six in 1939 and to five in 1949. This decline is partly offset by the increase in schools giving a semester of trigonometry which was not reported by this group in the first two reporting years but was given by thirteen in 1949.

High-school arithmetic for credit shows a steady decline, even including business arithmetic. There were seventy-eight of the schools giving general or business arithmetic, or both, in 1929. The number declined to fifty-four in 1939 and to twenty-three in 1949.

\section{FOREIGN LANGUAGE}

The biggest drop is shown in foreign language. German had all but vanished by 1929 , partly as a result of World War I, but was for a time replaced by Spanish. French had never been strong in these schools. Latin had once been a "must" for graduation in many of these schools, later sharing with Spanish as a requirement. In 1929 Latin was still taught in forty-five of these schools, five of them giving more than two units. In 1939 there were only twenty and in 1949 only eight, with none offering more than two units.

Spanish was found in fifty-seven schools in 1929, dropping to thirty-one in 1939 and to thirty in 1949. Not more than two units of work were found in any school at any of these periods. The large number of schools reporting one unit of Spanish some years reflects the number adding or dropping that language and giving at that time only the first or the second year. How many schools gave both of these languages the same year or during these two decades will make further interesting study. 


\section{NONACADEMIC COURSES}

The decrease in units of work offered in the five academic departments was much more than offset by increased opportunity in the other departments, especially in commercial subjects, manual arts, agriculture, and homemaking. Music, too, shows a steady growth. Other subjects, rather difficult to classify in these departments, have appeared infrequently, especially since 1939.

COMMERCIAL SUBJECTS

Typewriting was offered in thirty-five of these one hundred schools in 1929; in 1939 there were ninety-two and in 1949 typewriting was taught in one hundred per cent of them. The main change was in the amount of credit offered. In 1929 there was none of them giving two units but in 1939 there were twenty and in 1949 the number had risen to eighty-nine. This reflects the growth of typewriting as a vocational subject as well as for "personal use." A shortage of typists during the war accounts partly for the change.

This latter trend is shown in the increase of shorthand offerings in these one hundred schools, nearly always for one unit. It rose from twenty-nine in 1929 to seventy-three in 1939 and on up to eighty-five in 1949.

Bookkeeping was offered by thirty-two schools in 1929, with four of them giving only a one-semester course. In 1939 there were seventy-six of these schools giving bookkeeping and in 1949 there were eighty-eight, no onesemester course being reported in either of the last two years. General business, not reported in 1929 or 1939 , was shown by forty-two schools in 1949, usually for one unit of credit. Commercial law was rather steady for awhile, with forty-four schools in 1929 and forty nine in 1939, but twenty-one in 1949.

\section{MANUAL ARTS}

"Mechanical drawing" and "industrial arts" are always reported separately in the bulletin, though usually given by the same staff and in the same department. The tabulation for these two departments does not reveal a very accurate picture and a further count is needed to show the true status of this work. Furthermore, much "shop" work is given in vocational agriculture, thus extending this work for boys more than the figures indicate.

In 1929 there were seventeen of these schools reporting industrial arts and eleven reporting mechanical drawing, though some showed both. A majority of these schools then gave only one unit and almost none more than two. In 1939 there was a total of twenty-six in these two areas, the number growing to seventy-four in 1949 (fifty-seven in industrial arts and seventeen in drawing). The greatest change is in extent of the work. In 1949 there were thirty-two schools offering two units of industrial arts, five giving three units, and three giving four. In 1949 such courses as auto-mechanics, radio, 
trades and industries, pre-flight, and home mechanics are reported by a few schools, with credit ranging from one-half to four units.

\section{AGRICULTURE}

By 1929 most of the agriculture taught in these schools was vocational with the work subsidized and supervised by the Federal government. The numbers of schools giving one or more units rose from fifty-eight in 1929 to sixty-two in 1939 and on up to eighty-seven in 1949. The greatest change was in amount offered. In 1929 more than half of the schools were giving only one unit with very few offering over two units. In 1939 there were thirtyeight schools offering more than two units; while in 1949, seventy.

\section{HOMEMAKING}

Most of the enrollees in mechanical drawing, industrial arts, and agriculture are boys, just as most of the homemaking enrollees are girls. There are some mixed classes in all of these departments and in some schools there are special classes in manual arts for girls and in homemaking for boys. Starting with eighty-three schools giving homemaking courses in 1929, the number rose to ninety-four in 1939 and to ninety-nine in 1949. Again, the main change is in the amount of credit work provided, due largely to more and more of the schools sharing in the Federally aided program. In 1949 a majority of the schools gave over three units; while in 1929, none.

\section{MISCELLANEOUS SUBJECTS}

Music is the most frequently taught of the remaining subjects. In 1929 there were twenty-seven schools giving credit work in music, seventeen of them for only one unit. The total grew to fifty-one in 1939 and to fifty-seven in 1949. Again, an important change is in amount of credit work given. In 1939 nearly half of the schools giving music credit had more than one unit; in 1949 these schools were in the majority. It must be remembered that all of the hundred schools of this study have much music of a noncredit nature.

Free-hand drawing was offered in 1949 in eleven schools, rarely for more than one unit. Too rarely is this subject given for credit above the eighth grade.

Psychology steadily declined in number of schools teaching. This one-unit course continued in many high schools after the teacher-training department was dropped, gradually changing to a more general course. By 1929 there were still sixty-two of these schools teaching psychology, but they dropped to twenty-two in 1939 and to twenty in 1949.

Driver education, usually for one semester of credit, is found in an increasing number of high schools. Just getting started is a course in conservation of natural resources. Others reported by a few schools are: consumer education, diversified occupations, distributive education, and advanced civics. 